\title{
Sorption isotherms of parsnip
}

\author{
Ivan Kiryakov ${ }^{1}$, Mariya Georgieva ${ }^{1 *}$, Dimitar Atanasov ${ }^{1}$, and Nadya Arabadzhieva ${ }^{2}$ \\ ${ }^{1}$ Department of Industrial Heat Engineering, Technical Faculty, University of Food Technology, Plovdiv, Bulgaria \\ ${ }^{2}$ Department of Technical Mechanics and Mechanical Engineering, Technical Faculty, University of Food Technology, Plovdiv, \\ Bulgaria
}

\begin{abstract}
Parsnip is a root that has a number of useful nutrients. For this reason, in recent years it has been rehabilitated and is widely used in dried form in the food industry and for medicinal purposes. Knowledge of its equilibrium characteristics of the products has an important practical significance, which is expressed in the selection of a suitable drying regime, selection of optimal storage conditions, determination of the energy and the form of connection of water with the material, etc. Therefore, an experimental study was performed to determine the equilibrium moisture content of parsnip and equations describing the sorption and desorption isotherms of parsnip at a temperature of $20^{\circ} \mathrm{C}$ were derived. Its equilibrium moisture content at higher temperatures $\left(20,40\right.$ and $\left.60^{\circ} \mathrm{C}\right)$ was determined theoretically by the method of Pass and Slepchenko. All results are summarized in analytical, graphical and tabular form.
\end{abstract}

\section{Introduction}

In various technological processes, as well as in long-term storage, food products interact with the surrounding moist air in two ways:

- if the partial pressure of the steam on the surface of the material $\left(\mathrm{p}_{\mathrm{m}}\right)$ is greater than the partial pressure of the steam in the air $\left(p_{s}\right)-p_{m}>p_{s}$, a process of evaporation or desorption takes place;

- if $\mathrm{p}_{\mathrm{m}}<\mathrm{p}_{\mathrm{s}}$, then the material will be moistened by absorbing steam from the ambient air, ie. a sorption process takes place.

After some time, when $\mathrm{p}_{\mathrm{s}}$ and $\mathrm{p}_{\mathrm{m}}$ become equal, a state of thermodynamic and diffusion equilibrium occurs. The humidity of the material in the state of equilibrium is called the equilibrium humidity $\left(\mathrm{W}_{\mathrm{P}}\right)$. The set of equilibrium states at different relative humidity $(\varphi)$ and constant temperature of humid air $(t=$ const $)$, form an equilibrium isotherm, which depending on the way the equilibrium state is reached is called sorption or desorption isotherms $[1,2]$. The isotherm is graphically represented in a rectangular coordinate system $\varphi, \mathrm{W}_{\mathrm{P}}$, with a line whose equation is $\mathrm{W}_{\mathrm{P}}=\mathrm{f}(\varphi)$.

Knowledge of the equilibrium characteristics of the products has an important practical significance, which is expressed in the selection of a suitable drying regime, selection of optimal storage conditions, determination of the energy and the form of connection of water with the material, etc. $[1,4,5,6]$.

The purpose of this study is to determine the equilibrium isotherms of parsnips at different temperatures suitable for its drying.

The aim of this study is to determine experimentally the equilibrium moisture content of parsnip and to obtain dependences describing the sorption-desorption isotherms at different temperatures. They will be used in determining the conditions for storage and sizing of drying plants.

\section{Materials and methods}

The study was conducted experimentally with parsnip root (Pastinaca sativa L.), which is widely used in cooking and phytotherapy.

The static (tensimetric) method was used to determine the equilibrium humidity, which is recognized as standard for the determination of equilibrium isotherms. The method is based on reaching thermodynamic and diffusion equilibrium under static conditions, which allows to be achieved high accuracy. Its disadvantage is that the diffusion process is very slow and sometimes more than 20-30 days are required to reach equilibrium.

The research in this method proceeds in the following sequence.

A small amount of crushed material with a mass of 3$5 \mathrm{~g}$ is poured into pre-prepared weighing glasses. The glasses with the tested material are placed on a stand in special vessels (desiccators), at the bottom of which there are saturated solutions of appropriately selected salts. The desiccators maintain a constant relative humidity and temperature. The mass of the sample is monitored and weighed periodically. The equilibrium humidity of the product is determined by recording a constant mass at two consecutive weightings. The mass of the product was measured with a digital scale with an accuracy of 0.0001 g. The moisture content of the product at an equilibrium state is determined by the weighting method. For this purpose, the sample is dried in an atmospheric cupboard

\footnotetext{
* Corresponding author: $\underline{m}$ georgieva $@$ uft-plovdiv.bg
} 
at a temperature of $100+2{ }^{\circ} \mathrm{C}$, until a constant mass is reached.

A constant temperature of $20^{\circ} \mathrm{C}$ and a constant relative humidity were maintained in all samples of the experiment. To achieve a constant relative humidity in each desiccator were used saturated aqueous solutions of salts, having the ability to maintain a constant pressure of water vapor over themselves - Table 1 .

Table 1. Relative air humidity maintained by saturated aqueous solutions of salts at a temperature of $20^{\circ} \mathrm{C}$.

\begin{tabular}{|c|c|c|c|}
\hline Salts & $\varphi, \mathbf{\%}$ & Salts & $\varphi, \mathbf{\%}$ \\
\hline $\mathbf{N a O H}$ & 6.98 & $\mathrm{~K}_{2} \mathrm{CO}_{3}$ & 43.9 \\
\hline $\mathbf{L i C l}$ & 11.14 & $\mathrm{NaBr}$ & 58.7 \\
\hline $\mathbf{C H}_{3} \mathbf{C O O K}$ & 23.1 & $\mathrm{NaCl}$ & 75.4 \\
\hline $\mathbf{M g C l}_{\mathbf{2}}$ & 32.1 & $\mathrm{Na}_{2} \mathrm{SO}_{4}$ & 86.9 \\
\hline
\end{tabular}

The mathematical dependences obtained as a result of the experiments performed at a temperature of $20^{\circ} \mathrm{C}$ are presented by equations (1) and (2). Specialized "Table Curve 2D" software was used to process the experimental results. The equilibrium moisture of the material during sorption and desorption of parsnips is calculated for exact values of relative humidity in the range from 10 to $90 \%$ using the two equations cited above.

The drying process is usually carried out at temperatures higher than $20^{\circ} \mathrm{C}$. From the preliminary experiments performed it was found that a quality dried product is obtained by treatment with temperatures up to $80^{\circ} \mathrm{C}$. For this reason, equations of the type of equation (1) and equation (2) are derived theoretically by the method of Pass A. E. and Slepchenko L. I. at temperatures of 40,60 and $80^{\circ} \mathrm{C}$. The method gives good results at temperatures of $-20^{\circ} \mathrm{C}$ to $+100^{\circ} \mathrm{C}$ and is described in detail in [1].

\section{Results and discussion}

The relationships between $\mathrm{W}_{\mathrm{P}}$ и $\varphi$ are presented graphically in Fig. 1 and Fig. 2. The calculated values for the equilibrium moisture of the parsnip are presented in Table 2 and Table 3. An experimental study was performed, in which the value of the equilibrium moisture content of the tested material was measured at different values of relative humidity and a constant temperature of $20^{\circ} \mathrm{C}$. The remaining values of the equilibrium moisture content of parsnip at the same series of relative humidity and constant temperatures of 40,60 and $80^{\circ} \mathrm{C}$ were calculated by the method of Pass and Slepchenko [1].

Analytical consideration of sorption and desorption isotherms is other interesting alternative except that in tabular form. It is known that the sorption process depends on many different factors. Therefore, it is impossible to express the equilibrium isotherm with one equation.

Practically, large number of empirical and semiempirical equations are known for different products at a series of relative humidity $[2,3,4]$. The most commonly used are equations from the type: Brunauer, Emmett and
Teller (BET) or Guggenheim, Anderson and de Boer (GAB) $[4,5]$. In addition to being derived theoretically, all of these equations contain various constants that need to be determined experimentally. This is their drawback because it complicates working with them [5].

Table 2. Equilibrium moisture content of parsnip $\mathrm{W}_{\mathrm{P}}, \%$, determined by sorption at different temperatures.

\begin{tabular}{|c|c|c|c|c|}
\hline \multirow{2}{*}{$\boldsymbol{\varphi}, \boldsymbol{\%}$} & \multicolumn{4}{|c|}{ Temperature, ${ }^{\circ} \mathbf{C}$} \\
\cline { 2 - 5 } & $\mathbf{2 0}$ & $\mathbf{4 0}$ & $\mathbf{6 0}$ & $\mathbf{8 0}$ \\
\hline $\mathbf{1 0}$ & 2.55 & 2.27 & 2.05 & 2.11 \\
\hline $\mathbf{2 0}$ & 3.78 & 3.21 & 2.82 & 2.69 \\
\hline $\mathbf{3 0}$ & 4.94 & 4.14 & 3.58 & 3.20 \\
\hline $\mathbf{4 0}$ & 6.31 & 5.33 & 4.60 & 3.96 \\
\hline $\mathbf{5 0}$ & 8.07 & 6.97 & 6.08 & 5.21 \\
\hline $\mathbf{6 0}$ & 10.39 & 9.22 & 8.19 & 7.17 \\
\hline $\mathbf{7 0}$ & 13.43 & 12.26 & 11.11 & 10.04 \\
\hline $\mathbf{8 0}$ & 17.33 & 16.24 & 14.99 & 14.00 \\
\hline $\mathbf{9 0}$ & 22.22 & 21.30 & 19.99 & 19.26 \\
\hline
\end{tabular}

Table 3. Equilibrium moisture content of parsnip $W_{P}, \%$, determined by desorption at different temperatures.

\begin{tabular}{|c|c|c|c|c|}
\hline \multirow{2}{*}{$\boldsymbol{\varphi}, \boldsymbol{\%}$} & \multicolumn{4}{|c|}{ Temperature, ${ }^{\circ} \mathbf{C}$} \\
\cline { 2 - 5 } & $\mathbf{2 0}$ & $\mathbf{4 0}$ & $\mathbf{6 0}$ & $\mathbf{8 0}$ \\
\hline $\mathbf{1 0}$ & 4.91 & 3.35 & 2.84 & 1.74 \\
\hline $\mathbf{2 0}$ & 7.88 & 6.29 & 5.64 & 4.10 \\
\hline $\mathbf{3 0}$ & 9.86 & 8.70 & 7.92 & 6.54 \\
\hline $\mathbf{4 0}$ & 11.72 & 10.69 & 9.64 & 8.64 \\
\hline $\mathbf{5 0}$ & 14.43 & 12.87 & 11.36 & 10.46 \\
\hline $\mathbf{6 0}$ & 19.30 & 16.55 & 14.42 & 12.92 \\
\hline $\mathbf{7 0}$ & 28.22 & 23.97 & 20.93 & 18.13 \\
\hline $\mathbf{8 0}$ & 43.86 & 38.55 & 33.93 & 29.78 \\
\hline $\mathbf{9 0}$ & 69.95 & 65.06 & 57.48 & 53.47 \\
\hline
\end{tabular}

The resulting analytical relationships describing the sorption-desorption curves have the following form:

- Sorption -

$W_{P}=a+b \varphi^{1.5}+c \varphi^{3}+d \varphi^{0.5}$

- Desorption -

$W_{\mathrm{p}}=a+b \varphi+c \varphi^{2}+d \varphi^{3}+e \varphi^{4}+f \varphi^{5}$

where:

$\varphi$ - relative humidity of the air, $\%$;

$W_{P}$ - equilibrium moisture of parsnip, $\%$;

$a, b, c, d, e$ and $f$ are coefficients whose values are given in Table 4 and Table 5. 
The values of the average statistical error and the correlation factors $-r^{2}$ are shown in the mentioned above tables. The correlation equations obtained from our study are valid with a change in the relative humidity $\varphi$ between 0 and $90 \%$.

The results for the sorption and desorption isotherms given in Tables 2 and 3 are plotted in Fig. 1 and Fig. 2 .

As can be seen the increase in temperature leads to a shift of the equilibrium isotherms to the left in the entire temperature range. There is also a pronounced sorption hysteresis.

Equilibrium isotherms have the characteristic for capillary-porous colloidal bodies S-shaped appearance.

At low values of relative moisture content, the isotherms are convex to the abscissa axis, which indicates the type of moisture binding to the material, namely monomolecular adsorption. It is an insignificant part (Wp $=2-3 \%$ at $\mathrm{t}=20^{\circ} \mathrm{C}$ ) and decreases with increasing temperature. It is reported as the intersection of the tangent to the middle part of the isotherms and the abscissa axis. In the upper part all isotherms are convex to the ordinate axis. In this case, there is obviously poly molecular adsorption accompanied by capillary condensation.

Table 4. Coefficients for the equation of sorption.

\begin{tabular}{|c|c|c|c|c|}
\hline \multirow{2}{*}{ Coefficients } & \multicolumn{4}{|c|}{ Temperature, ${ }^{\circ} \mathbf{C}$} \\
\cline { 2 - 5 } & $\mathbf{2 0}$ & $\mathbf{4 0}$ & $\mathbf{6 0}$ & $\mathbf{8 0}$ \\
\hline $\mathbf{a}$ & -0.38273856 & -0.048789347 & -0.033030148 & -0.035567696 \\
\hline $\mathbf{b}$ & -0.0028610616 & -0.00392284605 & -0.0056044423 & -0.011118988 \\
\hline $\mathbf{c . 1 0 ^ { 5 }}$ & 2.1954425 & 2.3925727 & 2.4860421 & 2.9338755 \\
\hline $\mathbf{d}$ & 0.94951241 & 0.76561292 & 0.70537821 & 0.77966483 \\
\hline $\mathbf{r}^{\mathbf{2}}$ & 0.92189 & 0.999617 & 0.999508 & 0.9990405 \\
\hline Fitt Std Err & 2.50663654 & 0.16749819 & 0.18983583 & 0.26525111 \\
\hline
\end{tabular}

Table 5. Coefficients for the equation of desorption.

\begin{tabular}{|c|c|c|c|c|}
\hline \multirow{2}{*}{ Coefficients } & \multicolumn{4}{|c|}{ Temperature, ${ }^{\circ} \mathbf{C}$} \\
\cline { 2 - 5 } & $\mathbf{2 0}$ & $\mathbf{4 0}$ & $\mathbf{6 0}$ & $\mathbf{8 0}$ \\
\hline $\mathbf{a}$ & -0.043366495 & -0.010501125 & 0.1171139 & 0.041590359 \\
\hline $\mathbf{b}$ & 0.63480347 & 0.3499667 & 0.23696759 & 0.12256776 \\
\hline $\mathbf{c}$ & -0.016372805 & -0.0011705387 & 0.0054467215 & 0.0052283625 \\
\hline $\mathbf{d . 1 0}$ & 26.315302 & -1.9629321 & -20.729053 & -2.4667407 \\
\hline $\mathbf{e . 1 0}^{\mathbf{5}}$ & -2.4396239 & -8.1964409 & 1.4846188 & -2.3954358 \\
\hline $\mathbf{f . 1 0}^{\mathbf{8}}$ & 1.9255617 & 1.8821599 & 0.7727657 & 2.9669557 \\
\hline $\mathbf{r}^{\mathbf{2}}$ & 0.99990315 & 0.99998977 & 0.9998396 & 0.99983194 \\
\hline Fitt Std Err & 0.31012027 & 0.10239441 & 0.41112832 & 0.36545595 \\
\hline
\end{tabular}

\section{Conclusions}

1. The equilibrium moisture content values of parsnips at a constant temperature of $20^{\circ} \mathrm{C}$ was determined experimentally. At three higher values of constant temperature, $40, \quad 60$ and $80^{\circ} \mathrm{C}$ respectively, the equilibrium moisture content of the material was calculated theoretically by the methods of Pas and Slepchenko. The values obtained are shown in Tables 2 and 3
2. Equation (1), analytically describing the sorption isoterms of parsnips at four constant temperatures from 20 to $80^{\circ} \mathrm{C}$ and values of relative air humidity $\varphi$ varying from 0 to $90 \%$ respectively is derived.

3. The results obtained for the equilibrium moisture content of parsnips, determined at different constant values of temperature and relative air humidity are shown graphically in Figures 1 and 2 in the form of sorption and desorption curves.

4. The results obtained from this study will facilitate the work of specialists in the design and manufacture of dryers for parsnips and equipment for its storage. 


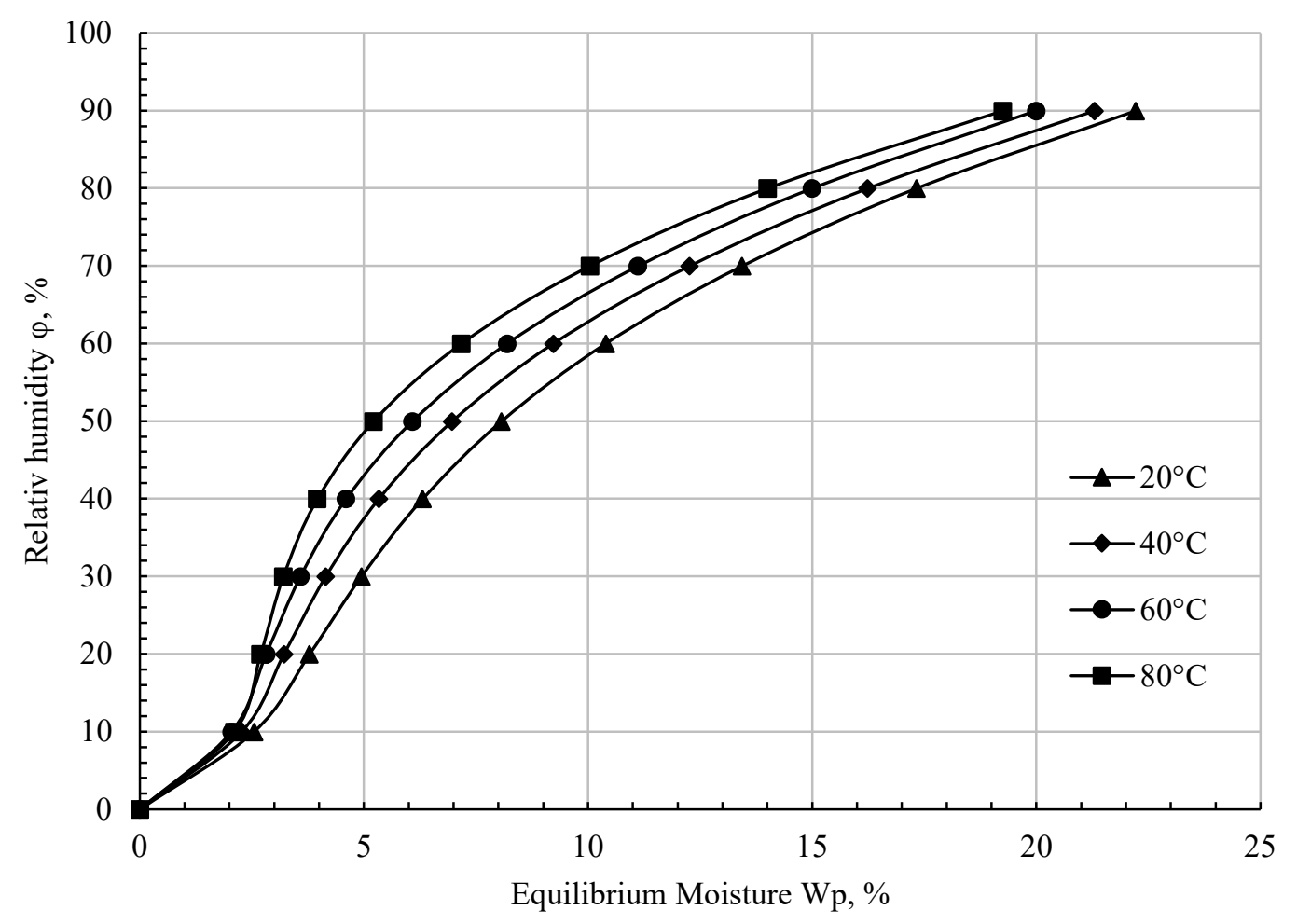

Fig. 1. Sorption isotherms of parsnip at different temperatures.

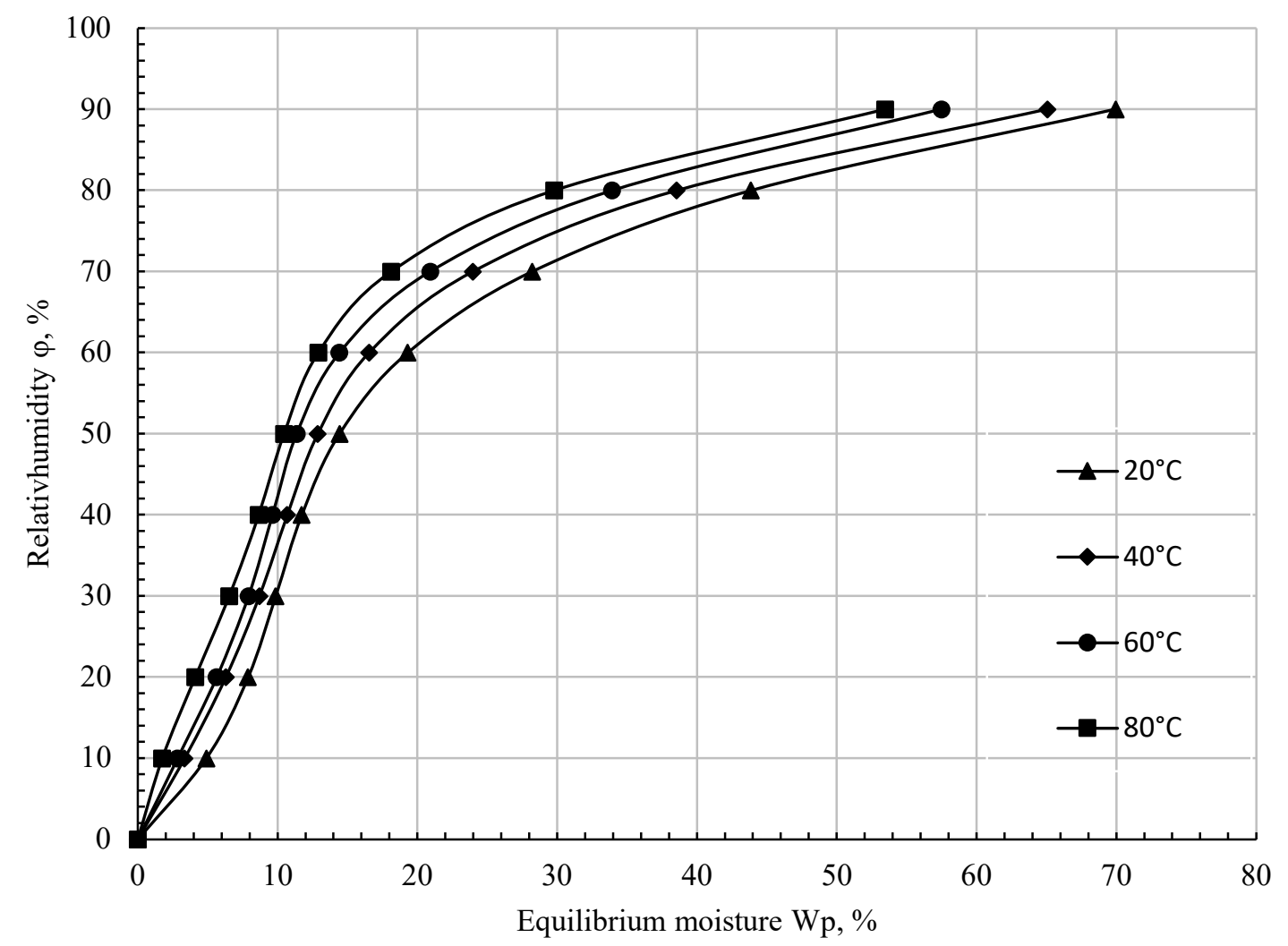

Fig. 2. Desorption isotherms of parsnip at different temperatures. 


\section{References}

1. A. Ginzburg, Fundamentals of the theory and technology of drying foods (Food Industry, Moscow, 1973)

2. I. A. Kiriakov, M. Georgieva, A. Tashev, T. Bogdanov, Proc. $5^{\text {th }}$ Int. Conf. Thermal Equip. Renew. Energy Rural Develop. (TE-RE-RD 2016, Golden Sands, 2016)

3. I. Kirjakov, M. Georgieva, A. Tashev, T. Bogdanov, Sci. Works UFT, LXII, 791-793 (2015)

4. M. Minchev, Drying equipment (Academic Publishing House of UFT, Plovdiv, 2012)

5. S. Nevenkin, Drying and drying equipment (Engineering, Sofia, 1993)

6. N. Penov, T. Petrova, Technology of dried fruits and vegetables(Academic Publishing House of UFT, Plovdiv, 2013) 